\title{
ANTHROPOMETRY AND SIZE GROUPS IN THE CLOTHING INDUSTRY
}

\author{
Monika Balach*, Marzanna Lesiakowska-Jablonska, Iwona Frydrych \\ Faculty of Material Technologies and Textile Design Institute of Architecture of Textile, Technical University of Lodz, \\ 116 Zeromskiego Street, Lodz 90-924, Poland. Tel. +48 4263655 22; \\ *E-mail: monikabalach@mail.com
}

\begin{abstract}
:
It appears that from generation to generation the anthropometric dimensions of the human population are changing. The aim of this paper was to examine the extent of these changes and the need for generating updated measurements for the clothing industry. The clothing industry uses mannequins and avatars to represent the modal group of the population. The industry tends to use three different categories for the human body shape (endomorphic, mesomorphic, and ectomorphic). The clothing industry should focus on specific measurements of the body rather than general categories and create more body shapes to satisfy customer needs. The paper also aimed at showing the problems faced by clothing designers. The traditional way of measuring takes into account only selected dimensions of the human body; this does not reflect the "true" overall body shape. The dimension tables used by the apparel industry are based on the fourth anthropometric photograph taken between 1987 and 1989. These tables are still in the use currently; however, after 30 years they are outdated and should be revised for the young contemporary generation. This study can be used for the development of new dimension tables as well as defining methods aimed at improving the quality of measurements for clothing engineering purposes. This is an important issue, because the National Institute of Anthropometry does not deal with such problems (the measurements are conducted mainly for understanding the human body shape rather than any other application), which means that anthropometric measurements are not ideally suited to applications of clothes fitting .
\end{abstract}

\section{Keywords:}

Anthropometric measurements, 3D body scanning, Normal distribution, Linear regression

\section{Introduction}

It is important to consider the effects of modern lifestyle on the human body shape. There are many factors, which must be considered such as dietary habits, the high standard of living, activity, or lack of, in everyday life, and current trends that all have an effect on the human shape necessitating the need to keep size tables up to date. Therefore, the clothing industry would benefit from the cyclic repetition of anthropometric photographs. Future improvements should be made to measurement methods and the presentation of results obtained. The use of detailed up-to-date dimension tables would greatly increase the accuracy of fit. Virtual fitting (using avatars) would also be highly beneficial, because the user could create several avatars with different body shapes, which would improve the fit quality for more customers.

Anthropometric measurements allow the mass production of clothing. Anthropological metrology defines measurements of large groups representing the population. Measurements, depending on whether they are full or part measurements, are conducted on a suitably large random sample of the population and subjected to the statistical processing for averaging and the selection of representative size groups. These human dimensions are grouped into size charts, which are used in the apparel construction. The measurements are separated into the figure-type and modal groups. Anthropometry makes it possible to build a human body shape in the form of anthropometric mannequins. These mannequins represent the average body size and shape of the human form in the given typological and size group [1].

Future development may take an advantage of robot kinematics and technology to create robotic mannequins, which simulate human movements and have sensors to detect temperature and pressure. This technology could be used to study how garments react to movement, for example, pressure points, friction, fabric bending, and draping.

Manual measurement of the human body shape is not sufficient to precisely map contours of the entire surface of the body, including those areas that are particularly important in clothingabutment surfaces (i.e., those on which the garment contacts the skin). Three-dimensional (3D) scanning technology is a modern innovative solution to accurately measure the contours and volume of the entire human body, offering enormous possibilities for the engineering of very accurately tailored clothing. There are several different noncontact scanning methods including moire topography, laser scanning, infrared scanning, and photogrammetry. In moire topography, light is shone through a linear grating onto the subject being scanned. The 3D shape of the subject causes the horizontal light pattern to be distorted. This distortion is recorded by a camera and is used to calculate a $3 \mathrm{D}$ map of the scanned object. Laser 
scanning projects the laser line onto an object and uses two cameras to calculate the position of points along the line using a triangulation. The horizontal beam is moved across the object to obtain a 3D point cloud. Infrared scanning uses triangulation in a very similar way to laser scanning. The main difference is that infrared radiation is used instead of laser light. Photogrammetry relies on parallax to map an object. Two cameras positioned at a certain parallax angle take photographs of the object. The difference between the two images is used to calculate the distance between points on the object. This spatial information is used to generate the $3 \mathrm{D}$ model $[2,3]$.

The clothing industry needs to define specific dimensions for the construction of clothing patterns. Therefore, an anthropometry plays such an important role in the clothing industries. It is important to know about the various body shapes and sizes in the population and the distribution of these in the population. As mentioned earlier, these forms and sizes are the basis of construction and gradation, while their distribution provides the basis for setting the percentage share of sizes in production orders. According to the normal distribution of the population, the highest percentage is usually the middle size of given size group, and the extremes are smaller [4].

The construction of size system is intended to reconcile two conflicting objectives. Clothing users want as many sizes as possible to allow them to purchase a garment that perfectly fits their body shape, while the clothing industry is opposed to make more size groups as doing so will expose the company to additional costs. The more measurements we have, the more size groups can be created which will result in more accurately fitting clothing. This will result in a better correlation between body features and the normal distribution. An increase in the number of size measurements will increase the level of satisfaction and better match the needs of "well-dressed" people [5].

The impact of correlation coefficient between the number of sizes and the growth rate of satisfaction is significant. A high degree of correlation creates the possibility of achieving a higher degree of satisfaction in a smaller number of sizes. One way to reduce the number of sizes may be to introduce the typological groups, but this solution will not be individual for each user. The clothing industry currently stores body dimension data on a computer. This data can then be used to create a virtual model (avatar) or mannequin [6].

\section{Experimental methods}

Experimental research was undertaken on a sample of students from the Lodz University of Technology. Prior to taking any measurements, certain criteria and assumptions were made regarding the population studied. The National Institute of Anthropometry in Wrocław, Poland, suggested a minimum sample of 250 men and 250 women. An important factor in this research was the adoption of age limits for the people surveyed. An age range of 20-30 years was chosen by the authors of this paper, suggesting that a group of young people, who are partaking in the higher education, could have the greatest physical dimensions in relation to the predicted adult standards.

Initially, body measurements were to be obtained using the 3D scanner as this is the fastest, most accurate method and can be used to examine cross-sections of the body and determine the mass distribution and overall body shape. Manual linear measurements are one dimensional, and they are therefore, poor indicators of body shape. During the initial stage of the research, a TC ${ }^{2}$ moire topography scanner was used; however, many people felt uncomfortable with this as the scanned image revealed all contours, volume data, and perceived imperfections of the body. Therefore, all measurements in this research were obtained manually. Women's height, chest circumference, waist circumference, and hip circumference were measured, while men's height, chest circumference, and waist circumference were measured [7-9].

Measurement of height for men and women was done in a standing position, with hands lowered and the head raised to the level of the horizontal visual axis. Measurements were taken with the subjects positioned in front of wallmounted measuring board, and the results obtained were to an accuracy of $1 \mathrm{~cm}( \pm 0.5 \mathrm{~cm})$. The circumference measurements for women were measured with a centimeter tape. The people were upright, breathing freely. Measurement of thoracic circumference for men and women was made using a centimeter tape, which was placed under the armpits and across the chest. Waist circumference for men and women was measured between the highest point of hip bone and the lower ribs. The hip circumference was measured only for women as a characteristic of their body shape. It was measured around the buttocks along the longest circumference line. Circumference measurements obtained were to an accuracy of $1 \mathrm{~cm}( \pm$ $0.5 \mathrm{~cm}$ ). The measurement tolerance was due to the fact that the people measured were dressed in lightweight outerwear.

\section{Analysis of results}

The data obtained were plotted into histograms to examine the frequency of people for each measurement with an interval of $2 \mathrm{~cm}$. Fig. 1 shows the frequency of women for each measured feature, and Fig. 2 shows the frequency of men for each measured feature.

Tables 1 and 2 summarize the obtained results. The height of women was in the range of $155-186 \mathrm{~cm}$, the chest circumference was between 78 and $106 \mathrm{~cm}$, the waist circumference was $59-90 \mathrm{~cm}$, while the women's hip circumference ranges from 83 to $115 \mathrm{~cm}$. For men, the height ranged from 162 to $200 \mathrm{~cm}$, the chest circumference was between 82 and $122 \mathrm{~cm}$, and the waist circumference varied from 69 to $111 \mathrm{~cm}$. Statistica software was used to calculate the parameters given in the following section.

\subsection{Analysis of measured quantities}

The results of the study show that for each woman's measurement, the measurement range interval obtained does 
a)

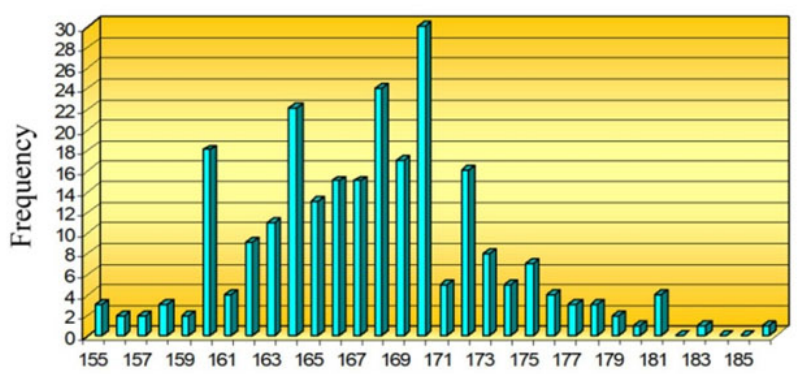

Height in cm

c)

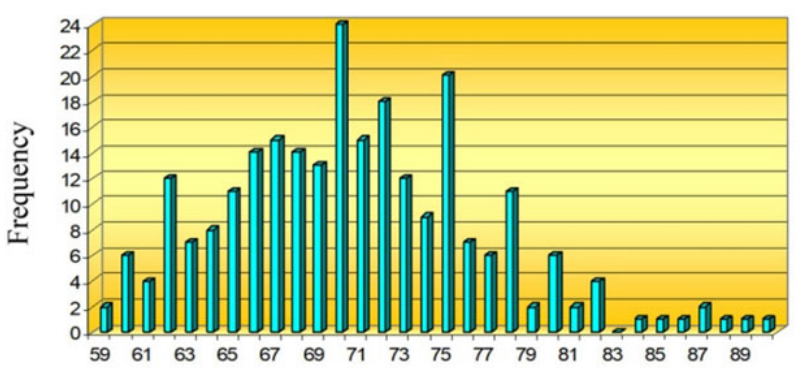

Waist Circumference in $\mathrm{cm}$ b)

Women Chest Circumference

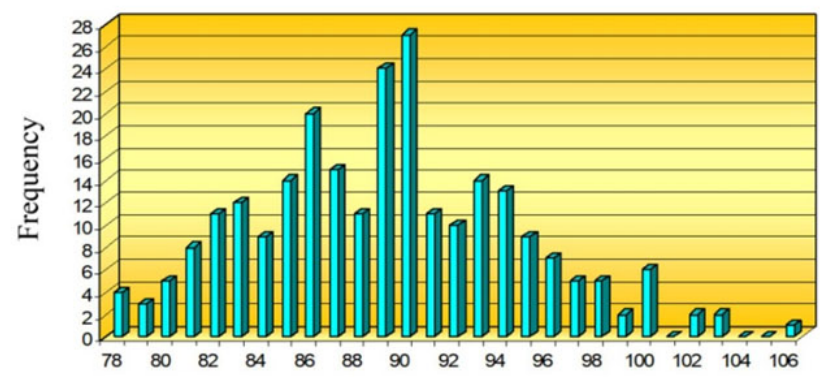

Chest Circumference in $\mathrm{cm}$

d)

Women Hips Circumference

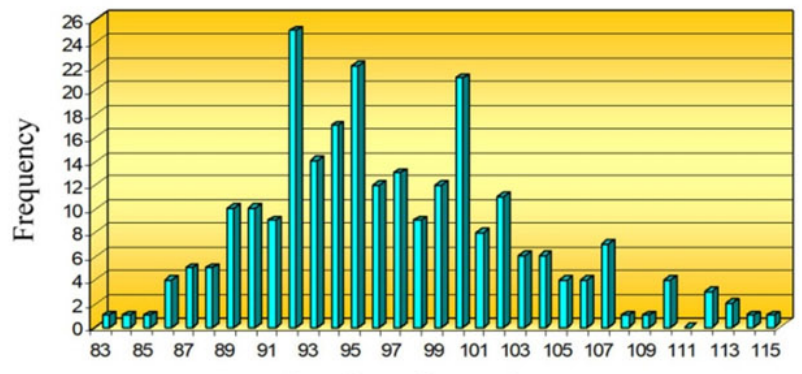

Hips Circumference in $\mathrm{cm}$

Figure 1. Histograms showing the frequency of women: a) height, b) chest circumference, c) waist circumference, and d) hip circumference

a)

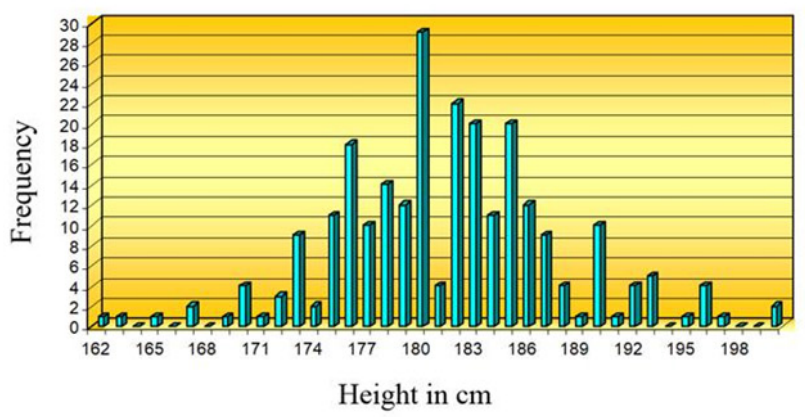

c)

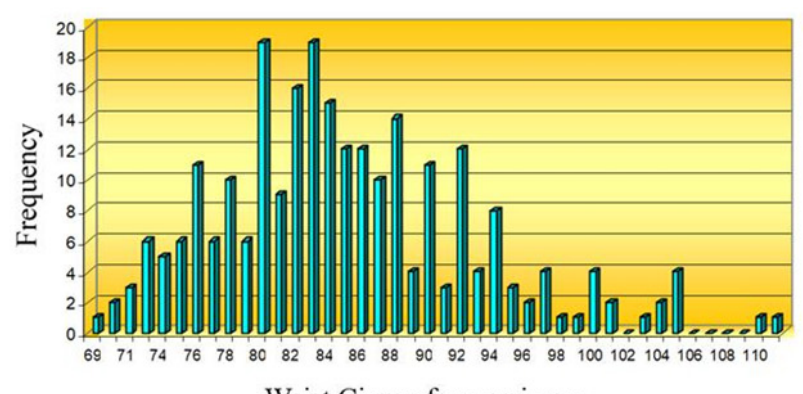

b)

Men Chest Circumference

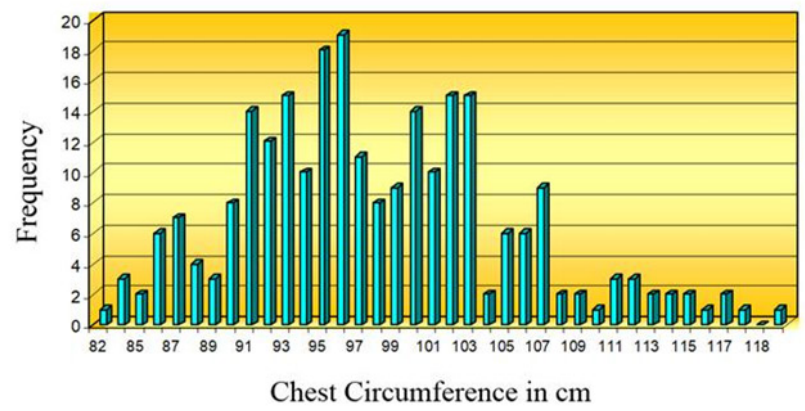

Figure 2. Histograms showing the frequency of men: a) height, b) chest circumference, and c) waist circumference

not match the typical measurement range of the examined feature (Table 1).

For the height and chest circumference, the measurement range includes values that are not found in the typical measurement range. For the waist circumference and hip circumference, the lower value of typical measurement range is significantly lower than the lower limit of the measured range.
The results of the study show that for each man's measurement, the measurement range obtained does not match the typical measurement range of the examined feature (Table 2). In the case of men's height, the measurement range interval and typical measurement range are very similar. This would suggest that there is a strong relationship between real and typical measurements. For the chest circumference and waist circumference, the lower and upper limits of the measurement range are greater than the lower and upper limits of the typical 
Table 1. Summary of statistical parameters analyzed for women

\begin{tabular}{|l|c|c|c|c|}
\hline & $\begin{array}{c}\text { Women's height, } \\
\text { cm }\end{array}$ & $\begin{array}{c}\text { Women's chest } \\
\text { circumference, cm }\end{array}$ & $\begin{array}{c}\text { Women's waist } \\
\text { circumference, cm }\end{array}$ & $\begin{array}{c}\text { Women's hip } \\
\text { circumference, cm }\end{array}$ \\
\hline Measurement range & $155-186$ & $78-106$ & $59-90$ & $83-115$ \\
\hline Mean & 167.6 & 89.0 & 70.7 & 96.7 \\
\hline Standard deviation & 5.49 & 5.46 & 6.07 & 6.01 \\
\hline $\begin{array}{l}\text { Typical measurement range } \\
\text { of the examined feature* }\end{array}$ & $151-184$ & $73-105$ & $52-89$ & $79-115$ \\
\hline Modal & 170 & 90 & 70 & 92 \\
\hline
\end{tabular}

*An interval of $\pm 3 d$ from the expected value was assumed (the expected value was estimated by summing the product of the examined feature with the probability of occurrence of this feature)

Table 2. Summary of statistical parameters analyzed for men

\begin{tabular}{|l|c|c|c|}
\hline & $\begin{array}{c}\text { Men's height, } \\
\text { cm }\end{array}$ & $\begin{array}{c}\text { Men's chest } \\
\text { circumference, cm }\end{array}$ & $\begin{array}{c}\text { Men's waist } \\
\text { circumference, cm }\end{array}$ \\
\hline Measurement range & $162-200$ & $82-122$ & $69-111$ \\
\hline Mean & 181.4 & 98.0 & 85.0 \\
\hline Standard deviation & 6.25 & 7.49 & 7.80 \\
\hline Typical measurement range of the examined feature* & $163-200$ & $76-120$ & $62-108$ \\
\hline Modal & 180 & 96 & 83 \\
\hline
\end{tabular}

${ }^{*}$ An interval of $\pm 3 \mathrm{~d}$ from the expected value was assumed (the expected value was estimated by summing the product of the examined feature with the probability of occurrence of this feature).

measurement range, respectively. Research also shows that the mean value for each measurement does not coincide with the modal value with differences between them of $1.4-2 \mathrm{~cm}$.

\subsection{Correlation between characteristics}

In all cases, there was a positive correlation between the characteristics tested. Correlation coefficients are summarized in Table 3 for women and men.

Table 3. Comparisons of correlation coefficients between the tested features

\begin{tabular}{|l|c|}
\hline Correlation between features & $\begin{array}{c}\text { Value of correlation } \\
\text { coefficient }\end{array}$ \\
\hline Women \\
\hline Height and chest circumference & 0.208 \\
\hline Height and waist circumference & 0.204 \\
\hline Height and hip circumference & 0.259 \\
\hline Chest and waist circumference & 0.685 \\
\hline Chest and hip circumference & 0.673 \\
\hline Waist and hip circumference & 0.683 \\
\hline Men & \\
\hline Height and chest circumference & 0.171 \\
\hline Height and waist circumference & 0.206 \\
\hline Chest and waist circumference & 0.774 \\
\hline
\end{tabular}

The relationship between the height and the other studied values shows a certain linear relationship; however, the relationship is weak. For men, there is a linear relationship found between waist and chest circumference. All correlation coefficients are positive. For women, it can be assumed that there is a significant linear relationship between the following values: waist circumference, hip circumference, and chest circumference. The linear relationship between the height and the other three measured features is very weak or absent. This suggests, therefore, that human height should not be combined in a linear relationship with other measured dimensions of the human body. It is true that there is a linear relationship, but it is so weak that judging on it with other values will be subject to a high degree of error.

\subsection{Linear regression function}

The linear regression function of the dependent variable $Y$ at the given values of the independent variable $X$ was calculated using the following equations:

$$
\begin{aligned}
& \hat{y}=a_{y} x+b_{y} \\
& \hat{x}=a_{x} y+b_{x}
\end{aligned}
$$

where $\bar{y}$ is the average value from the $Y$ population; $\bar{x}$ is the average value from the $X$ population; $x$. is the ith measurement of the $X$ feature; $y_{i}$ is the ith measurement of the $Y$ feature; $b_{x}$, $b_{y}$ are the constant numbers; $a x$, ay are the constant numbers.

The correlation coefficients were used to obtain the regression 
function between variables. Only in one case, there was no linear relationship between the two variables. In the other cases, there was a linear relationship. The linear relationship intensity ranged from a weak dependence through moderate to significant.

Due to the weak linear relationship, the regression function was considered in two ways. First, variable $Y$ was dependent on the independent variable $X$. Then, the two variables were swapped, so that the variable $X$ was dependent on the independent variable $Y$.

Fig. 3 shows an example of the relationship between two measured features. The numbers in the grid represent the frequency. The regression function was considered in two ways. First, variable $Y$ was dependent on the independent variable $X$. Then, we exchanged these two variables so that the variable $X$ was dependent on the independent variable $Y$. The blue lines represent the regression functions, in the example and $A B$ represents height $(A)$ and chest circumference $(B)$ and $B A$ represents chest circumference $(B)$ and height $(A)$. The green axis lines are reference lines, and their intersection coincides with the expected value for both measured features and marks the beginning of the reference system. The direction has been determined in such a way that with the change of value on one axis, the value on the second axis changes by the same value. Both regression functions as summarized in Table 4 also intersect at this point. The ellipse represents the standard deviation. To calculate the typical range of variability, the frequencies occurring in the area of the ellipse were counted and accumulated.
Based on the theory of normal distribution, it would be expected that the cumulative number in the typical range of variability should be $68.24 \%$ of the population, i.e., 171 observations out of 250 .

Based on the analysis as summarized in Tables $5 \mathrm{a}, 5 \mathrm{~b}$, and 6 , the results show that two cases needed to be rejected. In the first case, there was compatibility between the theoretical and real population, whereas in the second case there was no compatibility between the theoretical and real population. The difference between the real and theoretical population was in the range between 8 and 44 observations. The real values were smaller than the theoretical ones. This confirmed that the real distribution of measurements tested does not show any similarity to the normal distribution.

\section{Conclusions}

The industry-specific tables for dimensions that are representative of men for the fitting of clothing indicate the average height of $176 \mathrm{~cm}$ for all body types. The measurements in this study show that the mean height for the male model was $181.4 \mathrm{~cm}$, while the modal height was $180 \mathrm{~cm}$. Likewise, the situation was similar for the female model who was tested. The mean height for women was $167.6 \mathrm{~cm}$, and the modal value was $170 \mathrm{~cm}$. From the table of dimensions, the most commonly used by the clothing industry, the representative height for women used in the creation of clothing for all body types is $164 \mathrm{~cm}$. It follows that younger generations are taller than older generations, and this is an indication for the industry to adjust the dimension tables to the actual size of the population.

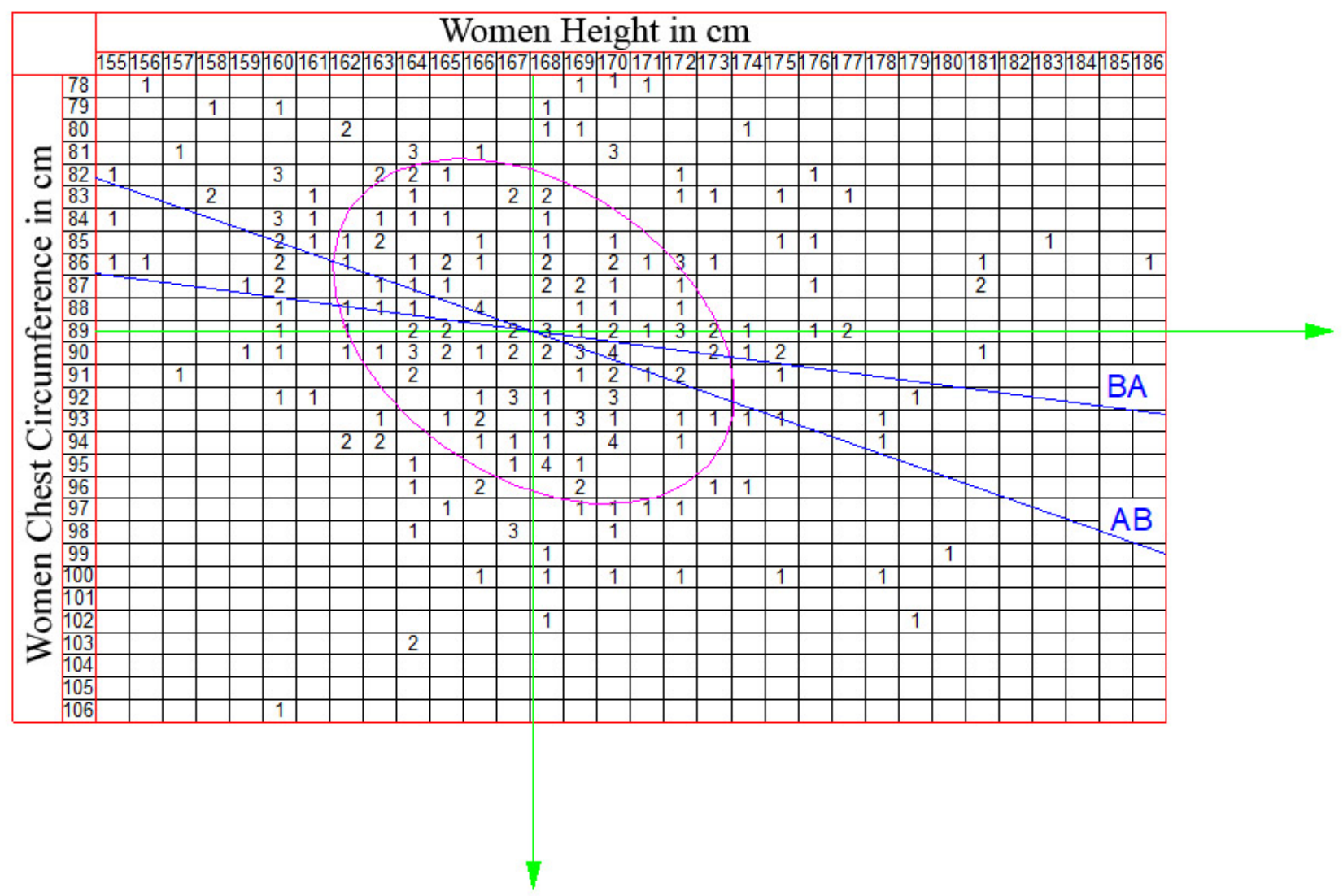

Figure 3. Schematic of the relationship between women's height and chest circumference 
Table 4. Regression function and linear relationship for each measured feature

\begin{tabular}{|c|c|}
\hline Regression function & Linear relationship \\
\hline$A B: Y=0.21 X+53.89$ & \multirow{2}{*}{ Relationship between women's height $(A)$ and chest circumference $(B)$} \\
\hline$B A: X=0.21 Y+148.89$ & \\
\hline$A C: Y=0.23 X+32.13$ & \multirow{2}{*}{ Relationship between women's height $(A)$ and waist circumference $(C)$} \\
\hline$C A: X=0.19 Y+154.20$ & \\
\hline$A D: Y=0.29 X+48.10$ & \multirow{2}{*}{ Relationship between women's height $(A)$ and hip circumference $(D)$} \\
\hline$D A: X=0.23 Y+145.40$ & \\
\hline$B C: Y=0.76 X+3.06$ & \multirow{2}{*}{ Relationship between women's chest $(B)$ and waist circumference $(C)$} \\
\hline$C B: X=0.62 Y+45.20$ & \\
\hline$B D: Y=0.77 X+28.17$ & \multirow{2}{*}{ Relationship between women's chest $(B)$ and hip circumference $(D)$} \\
\hline$D B: X=0.59 Y+31.95$ & \\
\hline$C D: Y=0.70 X+47.21$ & \multirow{2}{*}{ Relationship between women's waist $(C)$ and hip circumference $(D)$} \\
\hline$D C: X=067 Y+5.91$ & \\
\hline$F E: Y=0.21 X+160.8$ & \multirow{2}{*}{ Relationship between men's height $(E)$ and chest circumference $(F)$} \\
\hline$E F: X=0.14 Y+72.5$ & \\
\hline$G E: Y=0.26 X+159.3$ & \multirow{2}{*}{ Relationship between men's height $(E)$ and waist circumference $(G)$} \\
\hline$E G: X=0.17 Y+54.16$ & \\
\hline$G F: Y=0.81 X+29.15$ & \multirow{2}{*}{ Relationship between men's chest $(F)$ and waist circumference $(G)$} \\
\hline$F G: X=0.74 Y+12.48$ & \\
\hline
\end{tabular}

Table 5a. Summary of theoretical and real differences in the typical range of variation for women

\begin{tabular}{|l|c|c|c|}
\hline & $\begin{array}{c}\text { Women's height and hip } \\
\text { circumference, cm }\end{array}$ & $\begin{array}{c}\text { Women's height and waist } \\
\text { circumference, cm }\end{array}$ & $\begin{array}{c}\text { Women's height and chest } \\
\text { circumference, cm }\end{array}$ \\
\hline $\begin{array}{l}\text { Population size fulfilling } \\
\text { the criterion of belonging } \\
\text { to the correlation field }\end{array}$ & 131 & 127 & 135 \\
\hline $\begin{array}{l}\text { Expected number of } \\
\text { population meeting the } \\
\text { criterion }\end{array}$ & 171 & 171 & 171 \\
\hline $\begin{array}{l}\text { Difference between the } \\
\text { theoretical and real } \\
\text { population }\end{array}$ & 40 & 44 & 36 \\
\hline
\end{tabular}

Table 5b. Summary of theoretical and real differences in the typical range of variation: continued for women

\begin{tabular}{|l|c|c|c|}
\hline & $\begin{array}{c}\text { Women's chest } \\
\text { circumference and hip } \\
\text { circumference, cm }\end{array}$ & $\begin{array}{c}\text { Women's chest } \\
\text { circumference and waist } \\
\text { circumference, cm }\end{array}$ & $\begin{array}{c}\text { Women's waist } \\
\text { circumference, height, and } \\
\text { hip circumference, cm }\end{array}$ \\
\hline $\begin{array}{l}\text { Population size fulfilling } \\
\text { the criterion of belonging } \\
\text { to the correlation field }\end{array}$ & 174 & 161 & 163 \\
\hline $\begin{array}{l}\text { Expected number of } \\
\text { population meeting the } \\
\text { criterion }\end{array}$ & 171 & 171 & 171 \\
\hline $\begin{array}{l}\text { Difference between the } \\
\text { theoretical and real } \\
\text { population }\end{array}$ & -3 & 10 & 8 \\
\hline
\end{tabular}


Table 6. Summary of theoretical and real differences in the typical range of variation for men

\begin{tabular}{|l|c|c|c|}
\hline & $\begin{array}{c}\text { Men's waist } \\
\text { circumference and } \\
\text { chest, } \mathbf{~ c m}\end{array}$ & $\begin{array}{c}\text { Men's waist } \\
\text { circumference and } \\
\text { height, cm }\end{array}$ & $\begin{array}{c}\text { Men's chest } \\
\text { circumference and } \\
\text { height, cm }\end{array}$ \\
\hline $\begin{array}{l}\text { Population size fulfilling the criterion } \\
\text { of belonging to the correlation field }\end{array}$ & 170 & 144 & 146 \\
\hline $\begin{array}{l}\text { Expected number of population } \\
\text { meeting the criterion }\end{array}$ & 171 & 171 & 171 \\
\hline $\begin{array}{l}\text { Difference between the theoretical } \\
\text { and real population }\end{array}$ & 1 & 27 & 25 \\
\hline
\end{tabular}

It is necessary to develop a full anthropometric picture of the Polish population, or even complementary measurements, which, on a more representative sample, would arrive at a similar conclusion to this paper. Given the nonsymmetrical nature of the majority of distributions of studied measurements, it should be suggested to carry out research on a larger and more representative sample to confirm the hypothesis put forward in this paper, taking into account the percentage share of individual sizes in orders.

The analysis of research results confirms the theory that the real distributions of analyzed features do not show similarities with the normal distribution. Many researchers in their work point out that the analysis of certain measurable features of human body shows a distribution that is not a normal distribution. It was expected that the characteristics tested would be normal, but this was not confirmed by the statistical inference. The results need to be verified on the larger sample with 250 people. It is likely in countries with higher levels of ethnic diversity that the real distribution of measurements will have an even weaker link to the normal distribution [10].

The paper demonstrates the existence of significant linear relationship between the following values: waist circumference, hip circumference, and chest circumference. The linear relationship between the height and the other three measurements is very weak or nonexistent. It can be assumed that the human height is not linked by a significant linear relationship with the other three characteristics (hip, waist, and chest circumferences).

Proper development and implementation of new anthropometric measurements and fitting techniques using 3D scanning may result in the improved fit and functionality of clothing, thus leading to increased customer satisfaction. Therefore, this could be a valuable tool in paving the way for the future clothing technology development, which is necessary to remain at the forefront of the competitive consumer market. To gain a full understanding of the population anthropometry, this would involve collecting a large amount of data and the involvement of specialized research units.

\section{References}

[1] Poliński, Z. (2004). New anthropometric measurements as a necessary condition to improve the functionality of clothing. 2nd Scientific and Technical Conference CLOTECH (8-9 November 2004, Lodz, Poland)

[2] Fan, J., Yu, W., Hunter, L. (2004). Clothing appearance and fit: Science and technology. Woodhead Publishing Limited (Cambridge, England)

[3] Power, Jess, Apeagyei, P. R., Jefferson, A. M. (2011). Integrating $3 D$ scanning data \& textile parameters into virtual clothing. 2nd International Conference on $3 D$ Body Scanning Technologies. Hometrica Consulting (25-26 October 2011, Lugano, Switzerland)

[4] De Raeve, A., Cools, J., Vasile, S. (2018). 3D Body scanning as a valuable tool in a mass customization business model for the clothing industry. Journal of Fashion Technology and Textile Engineering. doi: 10.4172/2329-9568.S4-009

[5] Lesiakowska - Jabłońska, M. (1989). Digital reproduction of the phantom surface, PhD thesis, Technical University of Lodz, Department of Clothing and Measurement Systems (Lodz, Poland)

[6] D’Apuzzo, N. (2007). 3D body scanning technology for fashion and apparel industry. Proceedings of SPIE 6491, Videometrics IX, 649100 (29 January 2007, San Jose, USA)

[7] Hsu, C. -H. (2009). Developing accurate industrial standards to facilitate production in apparel manufacturing based on anthropometric data. Human Factors and Ergonomics in Manufacturing, 19(3), 199-211

[8] Zielinski, R. W. (1987). Hand-held statistic tables. Scientific and Technical Publishing House Warsaw (Warsaw, Poland)

[9] Yu, W. M., Harlock, S. C., Leaf, G. A. V., Yeung, K. W. (1997). Instrumental design for capturing three-dimension moire measurement. International Journal of Clothing Science and Technology, 9(4), 301-310

[10] Ostasiewicz, S., Rusnak, Z. U., Siedlecka (2011). Statistics and elements of theory and tasks (in Polish). University of Economics in Wroclaw (Wroclaw, Poland) 